Lanas, Maija \& Brunila, Kristiina (2019): Bad behaviour in school: a discursive approach, British Journal of Sociology of Education, DOI: 10.1080/01425692.2019.1581052

To link to this article: https://doi.org/10.1080/01425692.2019.1581052

\begin{abstract}
Disturbing, problematic, or challenging student behaviour is said to be among the greatest challenges facing today's school life. However, despite the apparent commonsensicalness of the issue, there is no commonly agreed upon definition for such events, and there is often very thin analysis of what actually becomes disturbed, challenged, or problematised in such instances. In this paper, disturbing behaviour is seen as a discursive practice that produces reality; it is a historically and socioculturally formed coming-together of various intersecting power-related discourses that make claims about individuals and contexts. Informed by poststructural approaches, this theoretical paper looks at how ideas of disturbing behaviour come to be formed within the discursive environment of school. The paper argues that behind the idea of disturbing behaviour are the ideas of a normal developmental course and an idealised student, as well as increasing emphasis on management and measurement in school.
\end{abstract}

Keywords: school, behaviour, student behaviour, poststructuralism, discourse

Maija Lanas*, University of Oulu, Department of Education

Kristiina Brunila, University of Helsinki, Department of Education 


\section{Bad behaviour in school: a discursive approach}

\section{Introduction: The Ambivalence of the Idea of Bad Behaviour}

Nearly one in three teachers, on average, reports losing "quite a lot of time" due to behavioural problems in school (OECD 2014, 9), and challenging or disturbing student behaviour is said to be among the greatest challenges currently facing schools (Brunila and Siivonen 2016; Närhi et al. 2015; Shaughnessy 2012; Sullivan et al. 2014). In the US, for instance, it has been argued that up to 50\% of teachers' and administrators' time is spent addressing issues related to problem behaviour (McKenna and Flower 2014). The response to this challenge has been to invent innumerable interventions, management strategies, methods, implementation programs, tools, tips, guidelines, and prosocial curricula (Anguiano 2001; Brainard 2001; Fairbanks, Sugai, Guardino, and Lathrop 2007; Gordon 2001; Haydon and Musti-Rao 2011; Hester, Hendrickson, and Gable 2009; Jeffrey, McCurdy, Ewing, and Polis 2009; Lake 2004; Lewis, Romi, Qui, and Katz 2005; McKenna and Flower 2014; Nahgahgwon, Umbreit, Liaupsin, and Turton 2010; Scarpaci 2007; Wheatley et al. 2009; Wright 2011; Wright and McLeod 2015). Similarly, problem behaviour (and its synonyms) has been studied extensively, especially in educational contexts, focusing on teachers' and trainers' perceptions, on causal attributions, or on allocating blame (Anguiano 2001; Axup and Gersch 2008; Erdogan et al. 2010; Hart and DiPerna 2017; Leffingwell 1977; Martin, Linfoot, and Stephenson 1999; Ratcliff, Jones, Costner, Savage-Davis, and Hunt 2010; Reglin, Akpo-Sanni, and LosikeSedimo 2012; Sun 2015; Verkuyten 2002). In short, addressing student misbehaviour has taken centre stage in schools in Global North and Western countries.

In the massive body of literature about the topic, several terms (disturbing, bad, challenging, problem, problematic, mis-, disruptive...) are used in overlapping ways to refer to roughly the same ideas. These terms are taken up in a rather commonsensical and naturalistic manner in educational discourse. However, these terms encompass a variety of diverse issues, including violence, silence, talkativeness, family background, representations considered masculine or feminine, expressions of subcultural identities, (lack of appropriate) emotional representation, littering, or handwriting (Koskela and Lanas 2016; Laws and Davies 2000; MacLure et al. 2012; Youdell 2003). For the purposes of this paper, seeking clear distinctions or definitions for these terms and ideas serves no purpose, as the paper aims to investigate the foundation upon which all these terms are based.

Of the vast variety of terms referring to the same ideas, we have chosen here to use "disturbing behaviour", but we use the term under erasure (Brunila 2009; Derrida 2003) — that is, we speak of it while simultaneously claiming that it does not exist as a static, nameable entity. We have chosen the 
Lanas \& Brunila (2019). Bad behaviour in school - discursive approach

term because it carries the least burden. For example, the "mis-" at the beginning of "misbehaviour" means "wrongly, badly, or unsuitably" (as in misunderstand, misapply, misallocate) and assumes some kind of binary (e.g., behave/misbehave). "Problematic behaviour", in turn, assumes some kind of inherent problem, while the concepts of "disturbing behaviour" and "challenging behaviour" enable us to ask what is actually disturbed or challenged. Of the two, we prefer "disturbing behaviour" because "disturbance" is more open than "challenge". While "challenge" entails the idea of some authority being challenged, "disturbing" can mean many things. Like "disrupting", the act of disturbing is also a poststructuralist concept—something, indeed, that many poststructuralist studies aspire to do in order to make openings for new understandings. For present purposes, then, disturbing behaviour is defined as action, speech, or conduct that in some way disturbs existing understandings.

Although, at a glance, disturbing behaviour seems straightforward and definable, several authors have called this into question (Kauffman and Landrum 2013; MacLure, Jones, Holmes, and MacRae 2012; Millei and Petersen 2015). For example, an extensive Ofsted study published in 2005 noted, "Defining challenging behaviour [...] has always been an unsatisfactory enterprise." Similarly, in their two-decade study (1968-1991) of teachers' definitions of good and bad behaviour in Finland, Koskela and Lanas (2016) concluded that even when the teachers used the same words, there was no common understanding of to what the words referred. Furthermore, multiple studies have found that behavioural expectations differ between schools, between classrooms, from one situation to another within classrooms, between the classroom and the playground, and from one school to another (Hempel-Jorgensen 2009; Koskela and Lanas 2016; Laws and Davies 2000; MacLure et al. 2012).

Nevertheless, even though the idea of disturbing behaviour does not seem to refer to a distinguishable or definable worldly phenomenon, it is understandable as an idea. In the discursive reality of education, disturbing behaviour of students is an idea that makes sense. In this paper, we are interested in how it comes to make sense. Informed by poststructuralist, critical, and discursive approaches, we propose that in order to make sense, an idea does not have to describe an existing worldly phenomenon, as long as it cites the surrounding, powerful discourses. This paper asks: Which discourses do the idea of disturbing behaviour cite in order to make sense?

The overall task of this paper is to look at the discursive conditions within which disturbing behaviour comes to exist, becomes defined as a problem, and in which solutions are suggested to solve it. In a field largely dominated by psychological and special education perspectives, we take an uncommon view by locating disturbing behaviour not within the student but within the broader discursive context in which meanings are assigned to acts. 
Lanas \& Brunila (2019). Bad behaviour in school - discursive approach

In what follows, we will argue that disturbing behaviour becomes discursively produced in the school every day as teachers interpret situations. We will claim that these teacher interpretations emerge within powerful discourses in education: discourse of normal developmental course, discourse of the ideal child, and discourse of management of students. These discourses set the backdrop against which events are read and responded to in schools. After that, we will work backward from these discourses to identify the broader historical-societal-discursive environments within which they, in turn, emerge and make sense: the rise of psy-disciplines, therapeutic ethos and medicalisation, managerialism and individualism, as well as existing societal power relations. We conclude by suggesting some implications for education.

\section{Discursive Production of Disturbing Behaviour}

Disturbing behaviour is discursively produced in schools every day as teachers interpret situations. Teachers are in a powerful position when making sense of events in school and interpreting circumstances. Simply a student's failure to meet a teacher's expectations may come to be seen as disturbing behaviour. For example, in Koskela and Lanas's research (2016), students were expected to take initiative and demonstrate independence in school, but only in ways that renewed the existing power relationship between teachers and students. Any initiative or demonstration of independence that challenged this relationship was likely to be characterised as disturbing. Similarly, Laws and Davies argue that to be recognised as legitimate and well-adjusted individuals, students need to avoid disturbing the power relations within the school by actively displaying their subjection and submission (Laws and Davies 2000, 214). Overall, to be seen as behaving well in the eyes of their teachers, students must perform minute, detailed readings to identify what constitutes appropriate behaviour in any situation. Failure to show commitment to teachers' established rules is likely to be inscribed as disturbing behaviour (Maclure et al. 2012).

The term "behaviour" implies that students' actions are a matter of choice and that teachers simply acknowledge these choices, but this is not the case. Firstly, teacher interpretations of behaviour are not under young people's control. Studies have long shown that interpretations of behaviour in school correlate with student skin tone, class, and gender (Ball 1981; Becker 1952; Cicourel and Kitsuse 1963, 1971 Meighan 1986; Rist 1970). The norm of a well-behaved student has been argued to be a particular cultural construction of studenthood that, for some, is almost impossible to perform (Grant 1997). Secondly, young people must continuously work out how to become credible subjects not only in the eyes of their teachers but also within multiple other reference groups: school, peers, home, and minority cultures (Lanas 2011; Lanas and Corbett 2011). This entails balancing multiple 
Lanas \& Brunila (2019). Bad behaviour in school - discursive approach

contradictory demands related to one's habitus, conduct, speech, and even emotions. Thirdly, if the school's repertoire of acceptable emotions does not match those experienced by the student in life and in school (e.g., anger or frustration), it may be impossible to secure positive recognition in school (MacLure et al. 2012, 464). Students may have very limited space to navigate these challenges. If students contest or refuse the forms of subjection made available to them in school, they may become unrecognisable subjects within the surrounding discourses - and where they do not make sense as subjects, the subject position "disturbing" may be the only available position left for them.

Although teachers are in a powerful position when making interpretations, they are not free in doing so. This is the nature of discourse. The idea of disturbing behaviour emerges within specific discursive frames that make common-sensical claims, for example, about pupils, childhood, youth, school, teachers, education, or upbringing. These frames produce meaning in relation to an individual's conduct (Brunila 2014, 2016). As we will show, these frames govern what teachers may perceive as problematic, how they may characterise and approach the perceived problem, and how they may position themselves as professional teachers in relation to the problem.

These discursive frames are produced as individuals read and respond to their surroundings. To simply refer to an event as "disturbing behaviour" already has certain implications; it defines an event as a disturbance, it locates the disturbance in the child or young person, and it defines the event in terms of chosen acts (behaviour). It follows that naming "disturbing behaviour" is a discursive practice (Bacchi and Bonham 2014) that produces reality and power relations. Overall, use of the term "disturbing behaviour" (or its synonyms) always implies some kind of power relation; the term is typically used when discussing someone who is under care or considered vulnerable (Brown 2014; Brunila et al. 2015). Children and youth are the groups most commonly addressed when discussing disturbing behaviour or its synonyms (although a quick internet search shows that similar language is applied to other vulnerable groups including people with disabilities, the elderly, and non-human animals). Notably, however, the term does not seem to be regularly applied when discussing adult men and women who are not under care.

In this way, the idea of disturbing behaviour is a union of intersecting societal and theoretical power-based discursive frames, which seem natural and are produced in everyday life. Next, we will direct our attention to these frames and how they operate.

\section{Wider Discourses Forming Disturbing Behaviour}

In the field of education, there are powerful ideas of a normal developmental course and of the ideal child, as well as an emphasis on the management of students. These ideas impact not only 
how teachers may see young people's behaviour but also how they may see their own position in relation to the behaviour of young people. These ideas do not stand alone but emerge within a wider discourse and ethos in education and society. Psy-disciplines, the therapeutic ethos, and medicalisation, as well as managerialism, individualism, and existing societal power relations, all shape the ideas that become understandable in educational institutions.

Figure 1 below visualises how these discursive frames and ideas come together. It is not meant to be any kind of model, as the discursive production of disturbing behaviour is not something that can be modelled. Rather, it is one possible visualisation of how the idea of disturbing behaviour emerges in the intersections of multiple overlapping discourses.

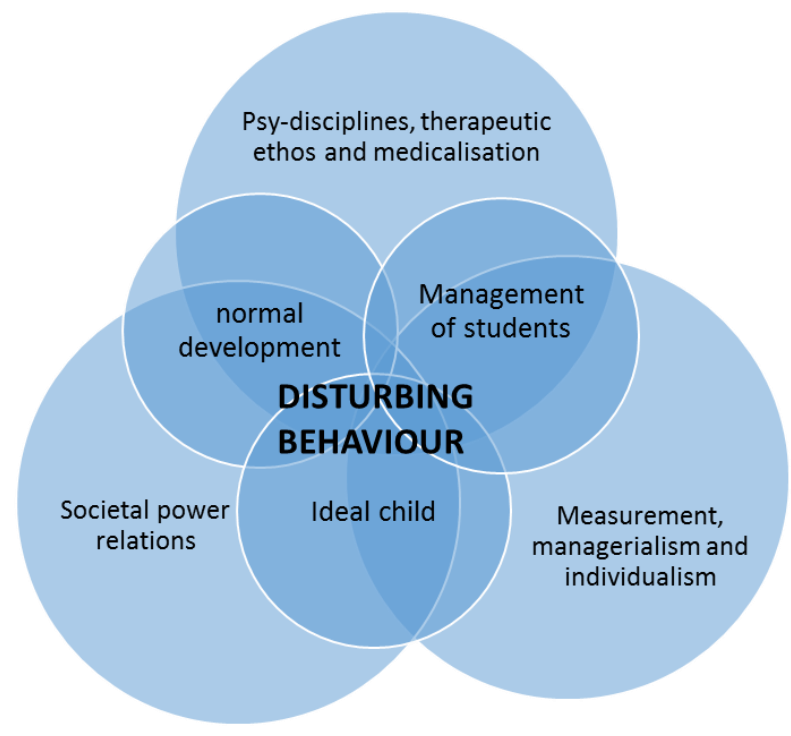

Figure 1: Discourses within which the idea of disturbing behaviour comes to make sense

Next, we will briefly outline the overlapping discourses of ideal child, normal development, and management. After this, we will go on to discuss the broader discourses identifiable behind such ideas.

\section{Ideal Child, Normal Developmental Course, and Management}

Although the term "ideal pupil" is over fifty decades old, it is still current. In the current educational climate, any student's agency that deviates from schools' expectations and norms is likely to be read through a discourse of normal development. If a student does not develop appropriately, an explanatory diagnosis is required. Laws and Davies (2000) suggest that this happens sooner rather than later in a young person's school career. They argue that within the dominant schooling discourse, students have about three months within which to manifest appropriate development and behaviour; after this time, measures are taken. If those measures are unsuccessful, a developmental psychological discourse will be employed to make sense of the failure. 
Lanas \& Brunila (2019). Bad behaviour in school - discursive approach

The powerful position of developmental psychology in education has been criticised since the 1980s across scientific fields and by multiple authors, most notably by Erica Burman. According to Burman (1994), developmental psychology and the related ideas of a normal developmental course are among the strongest regulatory discourses of childhood and youth. Burman and others claim that such normative discourses detach young people from their sociopolitical and historical contexts, providing homogenised descriptions of child development, idealising young people who fit into such descriptions and pathologising those who do not, and imposing uniformity based on the ideal while at the same time individualising and measuring gaps or differences from the norm (Burman 1994; MacLure et al. 2012; Watson 2016).

The idea of a normal developmental course has also been criticised for constructing children as objects of adult intervention and for installing such intervention as the foundation of education. Childhood studies (Alanen and Bardy 1990; James and Prout 1990) have directed attention to the material, cultural, and discursive construction of childhood and have emphasised the need to recognise the child readily as a political actor. Similarly, philosophers of education such as Bingham and Biesta (2010) have criticised approaches which assume that the political status of a child or youth depends on a prior psychological state and that children must be brought to speech by the educator. They argue that a young person should be referred to as a "speaker" rather than as a "learner".

Despite these well-known critiques, developmental psychology-based ideas of young people continue to circulate, shaping the subjectivities of young people as well as those of their teachersnot only dictating what different young people can be or should become, but also what educators of young people can be and become. As young people are not commonly acknowledged as full educational speakers or actors, and as behaviour is seen to require teacher control, educators become narrowly positioned as either "in control" or "out of control" of their classrooms (MacLure et al. 2012; Millei and Petersen 2015). Disruption in class comes to be understood both as the young person's lack of self-control and as the teacher's problem with management and control. Within such a discursive environment, the teacher is compelled to understand her role as one of management in order to maintain control of the classroom (Keat 2008; Millei and Petersen 2015). If students are seen as not behaving well, teachers risk consequences. The paradox of being a teacher is having to "manage the non-definable with professional certainty" (McMahon and Harwood 2016).

Like any actor, teachers work within the specific demands placed on them by surrounding discourses that provide them with tools for thinking and reading events. McGregor (2015) offers the example of how, when making sense of school engagement, teachers tend to draw from an entirely different set of discourses than, for instance, youth workers do. She found that while teachers drew 
Lanas \& Brunila (2019). Bad behaviour in school - discursive approach

primarily on discourses of individual responsibility for success or failure and related notions of youth deficits, youth workers recognised the social and economic pressures that shape the lives of young people and, consequently, their engagement with schools. ${ }^{1}$ This suggests that the different expectations placed on teacher and youth worker subjects within the surrounding discourses render different aspects of the students' situations visible and relevant. It is also notable that the vast existing literature identifies countless ways in which teachers can better manage behaviour but has virtually nothing to say about how teachers might analyse behaviour in its relation to social issues.

In summary, disturbing behaviour is shaped and formulated within existing overlapping ideas of a normal developmental course, an ideal of young people, and an emphasis on management of students. These, in turn, make sense within broader societal discourses, impacting educational thought: a) the psy-disciplines, therapeutic ethos, and medicalisation, b) the societal power relations, and c) measurement, managerialism, and individualism. Next, we will look at these broader societal discourses.

\section{The Psy-Disciplines, Therapeutic Ethos, and Medicalisation}

First, the rise of psy-disciplines, therapisation, and medicalisation provides the current popular language through which challenges, including those in school, are approached.

The psy-disciplines is a collective term for psychiatry, psychology, and psychoanalysis coined by Foucault in 1977 and subsequently elaborated on by others (Rose 1998). The term refers to how, from the eighteenth century on, these disciplines have become new forms of government, supplying the frames within which individuals understand, form, and regulate themselves, facilitating a shift from coercive control to "the conduct of conduct" and practices of self-formation. It has been argued that educational institutions play a central role in perpetuating the emergence and operation of the psy-disciplines as natural, inevitable, ethical, and liberating (Petersen and Millei 2016).

A number of sociologists and educationalists have argued that a therapeutic ethos has emerged within many Western education systems. This ethos draws on an eclectic range of psychological ideas and techniques that aim largely to enhance social and emotional learning and self-esteem. The term "therapeutic turn" refers to a multifaceted spectrum of discourses and social practices that discursively and institutionally pervade social and cultural life, including education. As Ecclestone et al. have shown, the psychological roots are diverse, ad hoc, and eclectic but commonly draw in different ways on the language, ideas, and techniques of popular psychology. Some programmes

\footnotetext{
${ }^{1}$ Research suggests that this varies between educational contexts: in Finland, wider societal aspects were also mostly missing in youth worker narratives (Brunila 2012, 2014; Brunila et al. 2015; Kurki and Brunila 2015)
} 
might be adapted from cognitive behavioural therapy and positive psychology while others draw on different strands of counselling, self-help, psychotherapy, and psychology, sometimes embellished by neuroscience (Ecclestone et al. 2015; see also Brunila 2014). For example, by way of response to widely perceived "crises" of children and youth, a diverse range of programmes, projects, and initiatives, sharing a common theme of enhancing emotional well-being, have become a routine feature of contemporary education systems in many countries. If there is no consideration of the societal roots of possible ill-being, these approaches risk victim-blaming. Collectively, such initiatives have been characterised as "therapeutic education" (Brown 2014; Brunila 2012, 2014; Ecclestone and Brunila 2015; Irisdotter, Aldenmyr, and Olsen 2016; Wright 2011; Wright and McLeod 2015).

Medicalisation refers to "the process whereby non-medical problems become routinely understood and handled as illnesses or disorders" (Malacrida 2004; Mills 2014). As Western society has come to react more dramatically (or quickly) to difference, and as the medical, educational, and psychiatric professions have developed, the range of behaviours identified or perceived as pathological has grown. This has increased psychiatric surveillance of a broad range of behaviors and signs that were once accepted as part of the continuum of human possibility but have now become problems to be resolved through expert practice, thus undermining tolerance (Malacrida 2004, 63).

Malacrida's (2004) study hints that medical professionals are not necessarily the ones calling the shots in Western society's shift toward medicalisation. Doctors are also pushed to give a diagnosis to students whose symptoms may not merit a diagnosis so that these students can be medicated to focus during school days. One possible reason for this is that, under the pressures of high-stakes testing, teachers cannot afford students who disturb instruction, and medication is used to replace pedagogy.

In the context of the psy-disciplines, medicalisation, and the therapeutic ethos, any young person in the classroom becomes an object of constant scrutiny in order to identify those who may not fit the norm and need treatment" (see also Riele 2006) by means of an intervention. Such processes serve to marginalise a minority of students in school and construct an idea of "normal". Marginalised children define a deviation from which "normal" children can recognise themselves as normal (MacLure et al. 2012, 455). Multiple studies have shown that even in the inclusive classroom, the discursively produced "other" may remain separate and excluded. Watson (2007) has argued that it is precisely by means of these processes that the "silent normal" sustains its position in an "unrecognized and unaddressed fear of difference, which becomes constructed around a potential 
Lanas \& Brunila (2019). Bad behaviour in school - discursive approach

threat to the order" (Watson 2016, 27). In this way, therapisation, medicalisation, and the psydisciplines implicitly risk contributing to othering practices in school.

\section{Societal Power Relations}

Second, societal power relations have a great impact on what kinds of conduct, speech, emotions, and actions are desirable for different individuals. As established earlier, for student agency to be described as disturbing, it need only disturb the existing and often implicit power relations in the society and school. Depending on the local history, these power hierarchies take different forms, but commonly race, class, finances, gender, sex, sexual orientation, or geography play a role. As stated by Allan and Harwood (2016, 185), “'[r]ace', class, and gender heighten the risk of psydiagnosis, while at the same time the very process of psy-diagnosis deflects attention from racialized, or gender discrimination, or poverty in the lives of children and young people" (see also Gillies 2011; Kurki and Brunila 2015).

Here, we will explicate this with two contexts. Firstly, in Britain, according to Youdell, At the level of the institution, discursive practices of Black youth/street culture are tacitly mediated through discourses that constitute these practices as inherently challenging to the school's (or individual teacher's) authority and, by extension, the broader White hegemony. (Youdell 2003, 15)

As one example, Youdell refers to Gillborn's (1990) observation of how a particular way of walking, common as a cultural practice among African-Caribbean boys, was interpreted by the school as a challenge to authority. Youdell further argues that black subcultural identities become presented as intrinsically anti-school and a challenge to authority. She calls this common-sense and institutional racism:

Such racism operates through the historicity — the sedimented meanings — of unrecognised and unacknowledged organisational and common-sense discourses which cite and inscribe the biological and/or cultural deficiency, hyper-sexuality, deviance, and threat of Blacknessthe discourse of a Black challenge to White hegemony. (Youdell 2003, 15)

This resonates with Lanas's (2011) observations in northern Finland, the second example provided here. Lanas's ethnography in a reindeer herding village school in Finnish Lapland showed that teachers responded to the explicit expression of local reindeer herding culture as if it was a deliberate challenge to school authority and national values. In the process, seemingly small everyday 
gestures became loaded with symbolic meaning. For example, the principal decided that civilisation of the villagers required that students should no longer smash their potatoes with a fork but should instead cut them with a knife. As a result, all students began smashing their potatoes, and this in turn came to be described as an act of disturbing behaviour.

In this way, in school, the well-behaved (ideal) child is one who, if not successfully representing the existing power hierarchies in the school and society, at least submits to them. Representations of youth subcultures or home cultures in school (if these are not dominant in the society) may come to be seen as disturbing sociocultural-historical power relations and are therefore regarded as disturbing behaviour (Lanas 2011; Youdell 2003).

\section{Measurement, Managerialism, and Individualism}

Third, when social challenges in school are labelled as behaviour, they are placed away from problematic power relations onto an individual student. In this way, the problem becomes individualised and managed within an individual.

Individualisation refers to the processes through which societal, social, institutional, or group phenomena are attributed to an individual and discussed as such. The ways in which the term "disturbing behaviour" (or its synonyms) is commonly applied is a textbook example of individualisation. Within schools, disturbing behaviour is usually envisaged as an expression of an individual deficit that lies "in" the person, their mindset, or their home — not in school. For example, Malacrida (2004) reports how, as a first response to students' problems in school, educators sent mothers to see psychiatrists or family therapists to resolve family difficulties (Malacrida 2004, 71). Similarly, in Koskela and Lanas's (2016) study of official teacher statements, there was no mention of the school context in either questions or answers throughout the four-page teacher statement form. In this way, the marital status of an individual mother (which was regularly mentioned in the form) was assigned greater significance than, for example, any ongoing peer issues within the school or relations between teachers and students. In addition, issues such as fighting were viewed as a characteristic of one individual rather than as a broader problem to be addressed in the school (Koskela and Lanas 2016, 467-468). Such individualising perspectives overlook the potentially constitutive role of schooling itself in producing behaviour.

Hardy (2015) suggests that this links to a broader organisational climate, in which schools must be seen as in control, even when this may not be the case (384). To convey such an impression, various guidelines, standards, tests, and programmes are employed and shape the organisations within which they are enacted. "In these ways, and with the assistance of specific systemic and individual 
programmes, students' behaviours became observable, governable, and manageable" (Hardy 2015, 384; see also Ikävalko and Brunila 2011). It has also been argued that schools' reorientation toward greater measurement of outcomes and accountability has pressured teachers to "perform" by producing the desired young people (Hempel- Jorgensen 2009; McGregor 2015). For example, Hempel-Jorgensen's research in high schools of low and high socioeconomic status indicates that increased emphasis on measurement leads to different conceptions of good behaviour for students from different life circumstances. In that study, the testing culture and the pressure to raise standards led to a performative and regulative mode of pedagogy in the low socioeconomic school. As a result, the "ideal pupil" in the low socioeconomic school was rendered passive, conforming to school discipline and the wishes of teachers, whereas in the high socioeconomic school, a competence-based pedagogy served to define the ideal pupil as a more equal and active learner. In short, conceptions of young people's disturbing behaviour are shaped by an increasing international emphasis on measurement and efficiency in education.

To summarise, the rise of psy-disciplines, the therapeutic ethos, medicalisation, individualisation, managerialism, and societal power relations define a backdrop against which it makes sense to speak of education in terms of a normal developmental course and the management of students. Against such a backdrop, the notion of an ideal child is also implicitly produced, although the term is rarely used. Instead, educators tend to speak of "appropriate behaviour", so creating the illusion of something that the young people in question can control. Through these powerful discourses, education subsumes broad historical contexts as well as young persons' actions, emotions, identity, circumstances, and motivations under a single term: behaviour — which in turn can assessed in a two-dimensional line with two ends: good or bad.

\section{Conclusion}

How we think about behaviour is a political act. The purpose of this paper was to map the complex network within which the seemingly simple idea of disturbing behaviour among young people in education emerges, makes sense, and begins to construct the world in its own terms. Such a mapping can never be exhaustive; instead, the aim was to elucidate the dynamic and complex production of disturbing behaviour. We would go so far as to suggest that disturbing behaviour is, in fact, the by-product of broader discursive practices and processes that have very little to do with 
behaviour. In visualising these processes, we sought to illuminate disturbing behaviour not as a definable static entity but as the intersection of a set of ideas and discourses.

The thrust of this paper was to elaborate and justify the argument that disturbing behaviour is a complex coming-together of multiple, overlapping discourses that combine in unprecedented ways and extend in different directions. Returning once more to the visualisation, we would direct the reader's attention to its centre, in between the shapes. This is because the important aspect of the visualisation is not the circular shapes but the shapes formed at the centre by the lines as the different discourses overlap and combine.

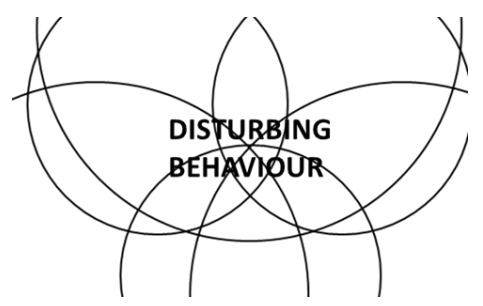

\section{Figure 2: Disturbing behaviour as travelling lines}

In this view, disturbing behaviour has no boundaries or borders. In fact, rather than a combination of circular shapes, it should be visualised as the quite random shape of lines forming at the intersections of wider sociohistorical discourses and heading in various directions.

For education, this means that disturbing behaviour can never be extinguished simply by correcting the behaviour of a child seen to be in need of correction. Instead, educators should interrogate the following core notion. When we set out to abolish disturbing behaviour, what are we, in fact, seeking to abolish? Is it littering? Is it violence? Is it student demands to participate in the construction of implicit expectations in education? Is it non-white, non-middle-class cultures? Is it children who seem unproductive and may undermine the school's record? Is it unhappy children who bring their pain to school? We must look more carefully at our end goals.

\section{References}

Alanen, L., \& Bardy, M. (1990). Lapsuuden aika ja lasten paikka : Tutkimus lapsuudesta yhteiskunnallisena ilmiönä. Helsinki: Sosiaalihallitus.

Allan, J., \& Harwood, V. (2016). The risk factors for psy-diagnosis? Gender, racialization and social class. In E. B. Petersen, \& Z. Millei (Eds.), Interrupting the psy-disciplines in education (pp. 185-202). London \& New York: Palgrave MacMillan.

Anguiano, P. (2001). A first-year teacher's plan to reduce misbehaviour in the classroom. Teaching Exceptional Children, 33(3), 52. 
Lanas \& Brunila (2019). Bad behaviour in school - discursive approach

Axup, T., \& Gersch, I. (2008). The impact of challenging student behaviour upon teachers' lives in a secondary school: Teachers' perceptions. British Journal of Special Education, 35(3), 144-151. doi:10.1111/j.1467-8578.2008.00388.x

Bacchi, C and Bonham, J. (2014). Reclaiming discursive practices as an analytic focus: political implications. Foucault Studies 17, 173-192.

Ball, S. 1981. Beachside Comprehensive, A Case Study in Secondary Schooling. London: Cambridge University Press.

Becker, H. 1952. Social class variations in the teacher-pupil relationship. Journal of Educational Sociology 25. 451-466.

Bingham, Charles \& Biesta, Gert. (2010). Jacques Rancière: Education, truth, emancipation. London: Continuum.

Brainard, E. (2001). Classroom management: Seventy-three suggestions for secondary school teachers. Clearing House, 74(4), 207.

Brown, K. 2014. Questioning the 'Vulnerability zeitgeist': Care and Control Practices with 'Vulnerable' Young People. Social Policy \& Society, 13(3).

Brunila, K. \& Siivonen, P. (2014). Preoccupied with the Self. Towards self-responsible, enterprising, flexible, and self-centred subjectivity in education. Discourse: Studies in the Cultural Politics of Education 37(1), 56-69.

Burman, E. (1994). Deconstructing developmental psychology. London: Routledge.

Cicourel, A. \& Kitsuse, J. 1963. The Educational Decision Makers. Indianapolis: Bobbs-Merril

Cicourel, A. \& Kitsuse, J. 1971. The social organisation of High School and Deviant Adolescent Careers. In Cosin, B., Dale, I., Esland, G. \& Swift, D. (Eds.) 1971. School and Society, a Sociological Reader. London: Routledge and Kegan Paul and Open University Press.

Derrida, J. (2003). Platonin apteekki ja muita kirjoituksia. Helsinki: Gaudeamus.

Ecclestone, K. \& Brunila, K. (2015). Governing emotionally-vulnerable subjects and the therapisation of social justice. Pedagogy, Culture \& Society 23(4), 485-506.

Erdogan, M., Kursun, E., Sisman, G. T., Saltan, F., Gök, A., \& Yildiz, I. (2010). A qualitative study on classroom management and classroom discipline problems, reasons, and solutions: A case of information technologies class. Educational Sciences: Theory \& Practice, 10(2), 881-891.

Fairbanks, S., Sugai, G., Guardino, D., \& Lathrop, M. (2007). Response to intervention: Examining classroom behaviour support in second grade. Exceptional Children, 73(3), 288-310.

Gillborn, D. (1990) 'Race', Ethnicity and Education: teaching and learning in multi-ethnic schools. London: Unwin Hyman. 
Lanas \& Brunila (2019). Bad behaviour in school - discursive approach

Gillies, V. (2011). Social and emotional pedagogies: critiquing the new orthodoxy of emotion in classroom and behaviour management British Journal of Sociology of Education, 32 (2), 185202

Gordon, D. G. (2001). Classroom management. Music Educators Journal, 88(2), 17.

Grant, B. (1997). Disciplining students: The construction of student subjectivities. British Journal of Sociology of Education, 18(1), 101-114. doi:10.1080/0142569970180106

Hardy, I. (2015). Education as a 'risky business': Theorising student and teacher learning in complex times. British Journal of Sociology of Education, 36(3), 375-394. doi:10.1080/01425692.2013.829746

Hart, S. C., \& DiPerna, J. C. (2017). Teacher beliefs and responses toward student misbehaviour: Influence of cognitive skill deficits. Journal of Applied School Psychology, 33(1), 1-15. doi:10.1080/15377903.2016.1229705

Haydon, T., \& Musti-Rao, S. (2011). Effective use of behaviour-specific praise: A middle school case study. Beyond Behaviour, 20(2), 31-39.

Hempel- Jorgensen, A. (2009). The construction of the 'ideal pupil' and pupils' perceptions of 'misbehaviour' and discipline: Contrasting experiences from a low-socio- economic and a high- socio- economic primary school. British Journal of Sociology of Education, 30(4), 435448. doi:10.1080/01425690902954612

Hester, P. P., Hendrickson, J. M., \& Gable, R. A. (2009). Forty years later -- the value of praise, ignoring, and rules for preschoolers at risk for behaviour disorders. Education \& Treatment of Children, 32(4), 513-535.

Irisdotter Aldenmyr, S., \& Olson, M. (2016). The inward turn in therapeutic education: an individual enterprise promoted in the name of the common good. Pedagogy, Culture and Society, 24(3), $387-400$.

James, A., \& Prout, A. (1990). Constructing and reconstructing childhood : Contemporary issues in the sociological study of childhood. London: Falmer.

Jeffrey, J. L., McCurdy, B. L., Ewing, S., \& Polis, D. (2009). Classwide PBIS for students with EBD: Initial evaluation of an integrity tool. Education \& Treatment of Children, 32(4), 537-550.

Kauffman, J. M., \& Landrum, T. J. (2013). Characteristics of emotional and behavioural disorders of children and youth (10. ed ed.). Boston Mass.: Pearson.

Keat, J. (2008). Decreasing child defiance: Is inquiry indispensable? Springer Science \& Business Media B.V. doi:10.1007/s10643-008-0262-3 
Lanas \& Brunila (2019). Bad behaviour in school - discursive approach

Koskela, A., \& Lanas, M. (2016). Fabricating expert knowledge of the behaviour of problematic students. Pedagogy, Culture \& Society, 24(3), 459-471. doi:10.1080/14681366.2016.1196232

Lake, V. E. (2004). Ante up: Reconsidering classroom management philosophies so every child is a winner. Early Child Development \& Care, 174(6), 565-574. doi:10.1080/0300443042000187077

Lanas, M., \& Corbett, M. (2011). Disaggregating student resistances, analysing what students pursue with challenging agency. Young, the Scandinavian Journal of Youth Studies, 19(4), 415-432.

Lanas, M. (2011). Smashing potatoes : Challenging student agency as utterances. Oulu: University of Oulu.

Laws, C., \& Davies, B. (2000). Poststructuralist theory in practice: Working with "behaviourally disturbed" children. International Journal of Qualitative Studies in Education, 13(3), 205-221. doi:10.1080/09518390050019631

Leffingwell, R. J. (1977). Misbehaviour in the classroom--anxiety, a possible cause. Education, 97(4).

Lewis, R., Romi, S., Qui, X., \& Katz, Y. J. (2005). Teachers' classroom discipline and student misbehaviour in australia, china and israel. Teaching \& Teacher Education, 21(6), 729-741. doi:10.1016/j.tate.2005.05.008

MacLure, M., Jones, L., Holmes, R., \& MacRae, C. (2012). Becoming a problem: Behaviour and reputation in the early years classroom. British Educational Research Journal, 38(3), 447-471. doi:10.1080/01411926.2011.552709

Malacrida, C. (2004). Medicalization, ambivalence and social control: Mothers' descriptions of educators and ADD/ADHD. Health: An Interdisciplinary Journal for the Social Study of Health, Illness \& Medicine, 8(1), 61-80. doi:10.1177/1363459304038795

Martin, A. J., Linfoot, K., \& Stephenson, J. (1999). How teachers respond to concerns about misbehaviour in their classroom. Psychology in the Schools, 36(4), 347.

McGregor, G. (2015). Counter-narratives that challenge neo-liberal discourses of schooling 'disengagement': Youth professionals informing the work of teachers. British Journal of Sociology of Education, , 1-13. doi:10.1080/01425692.2015.1113859

McKenna, J. W., \& Flower, A. (2014). Get them back on track: Use of the good behaviour game to improve student behaviour. Beyond Behaviour, 23(2), 20-26.

McMahon, S., \& Harwood, V. (2016). Confusions and conundrums during final practicum: A study of preservice teachers' knowledge of challenging behaviour. In E. B. Petersen, \& Z. Millei (Eds.), Interrupting the psy-disciplines in education (pp. 145-166). London \& New York: Palgrave MacMillan. 
Lanas \& Brunila (2019). Bad behaviour in school - discursive approach

Meighan, R. 1986. A Sociology of Educating. Second edition. London: Cassell Educational Ltd. 293352.

Millei, Z., \& Petersen, E. B. (2015). Complicating 'student behaviour': Exploring the discursive constitution of 'learner subjectivities'. Emotional \& Behavioural Difficulties, 20(1), 20-34. doi:10.1080/13632752.2014.947097

Mills, China (2014). Decolonizing Global Mental Health: The Psychiatrization of the Majority World. New York: Routledge.

Nahgahgwon, K. N., Umbreit, J., Liaupsin, C. J., \& Turton, A. M. (2010). Function-based planning for young children at risk for emotional and behavioural disorders. Education \& Treatment of Children, 33(4), 537-559.

Närhi, V., Kiiski,T., Peitso, T. \& Savolainen, H. (2015) Reducing disruptive behaviours and improving learning climates with class-wide positive behaviour support in middle schools. European Journal of Special Needs Education, 30(2), 274-285, DOI:10.1080/08856257.2014.986913

OECD. (2014). A Teachers' guide to TALIS. Retrieved 21.9.2018 from http://www.oecd.org/education/school/TALIS-Teachers-Guide.pdf

OFSTED. (2005). A study of children and young people who present chalenging behaviour. Retrieved from http://www.scie-socialcareonline.org.uk/a-study-of-children-and-young-people-whopresent-challenging-behaviour/r/a11G00000017tcxIAA

Petersen, E.B. \& Millei, Z. (2016) Introduction. (pp. 1-12) E.B. Petersen \& Z. Millei (Eds) Interrupting the Psy-Disciplines in Education. London \& New York: Palgrave MacMillan.

Ratcliff, N. J., Jones, C. R., Costner, R. H., Savage-Davis, E., \& Hunt, G. H. (2010). The elephant in the classroom: The impact of misbehaviour on classroom climate. Education, 131(2), 306-314.

Reglin, G., Akpo-Sanni, J., \& Losike-Sedimo, N. (2012). The effect of a professional development classroom management model on at-risk elementary students' misbehaviours. Education, 133(1), 3-18.

Rose, N. (1998). Inventing our selves: Psychology, power and personhood. Cambridge \& New York: Cambridge University Press.

Riele, K. t. (2006). Youth 'at risk': Further marginalizing the marginalized? Journal of Education Policy, 21(2), 129-145. doi:10.1080/02680930500499968

Rist, R. 1970. Student Social Class and Teacher Expectations: The Self-Fulfilling Prophecy in Ghetto Education. Harvard Educational Review 40, 411-451. 
Lanas \& Brunila (2019). Bad behaviour in school - discursive approach

Scarpaci, R. T. (2007). IOSIE: A method for analyzing student behavioural problems. Clearing House, 80(3), 111-116.

Shaughnessy, J. (2012). The challenge for English schools in responding to current debates on behaviour and violence. Pastoral Care In Education, 30(2), 87-97. doi:10.1080/02643944.2012.679954

Sullivan, A. M., Johnson, B., Owens, L., \& Conway, R. (2014). Punish Them or Engage Them? Teachers' Views of Unproductive Student Behaviours in the Classroom. Australian Journal of Teacher Education, 39(6).http://dx.doi.org/10.14221/ajte.2014v39n6.6

Sun, R. C. F. (2015). Teachers' experiences of effective strategies for managing classroom misbehaviour in Hong Kong. Teaching \& Teacher Education, 46, 94-103. doi:10.1016/j.tate.2014.11.005

Verkuyten, M. (2002). Making teachers accountable for students' disruptive classroom behaviour. British Journal of Sociology of Education, 23(1), 107-122. doi:10.1080/01425690120102881

Watson, K. (2016). 'Silences' in the 'inclusive' early childhood classroom: Sustaining a 'taboo'. In E. B. Petersen, \& Z. Millei (Eds.), Interrupting the psy-disciplines in education (pp. 13-31). London $\&$ New York: Palgrave MacMillan.

Wheatley, R. K., West, R. P., Charlton, C. T., Sanders, R. B., Smith, T. G., \& Taylor, M. J. (2009). Improving behaviour through differential reinforcement: A praise note system for elementary school students. Education \& Treatment of Children, 32(4), 551-571.

Wright, K. \& McLeod, J. (2015) Rethinking Youth Wellbeing: Critical Perspectives. Singapore: Springer.

Wright, K. (2011). The rise of therapeutic society, New York: Academia Publishing.

Youdell, D. (2003). Identity traps or how black students fail: The interactions between biographical, sub-cultural, and learner identities. British Journal of Sociology of Education, 24(1), 3-20. doi:10.1080/0142569032000043579 